Earth Syst. Sci. Data Discuss., doi:10.5194/essd-2016-29, 2016

Manuscript under review for journal Earth Syst. Sci. Data

Published: 28 July 2016

(c) Author(s) 2016. CC-BY 3.0 License.

(c) (i)

\title{
Hydrochemical assessment of Semarang area using multivariate statistics: A sample based dataset
}

\author{
Irawan Dasapta Erwin ${ }^{1}$ and Putranto Thomas Triadi ${ }^{2}$ \\ ${ }^{1}$ Faculty of Earth Sciences and Technology, Institut Teknologi Bandung, Jalan Ganesa No. 10, \\ Bandung - 40132, Indonesia \\ ${ }^{2}$ Faculty of Engineering, Universitas Diponegoro, Jalan Prof. H. Soedarto, SH, Tembalang, Kota \\ Semarang - 50275, Indonesia \\ Correspondence to: Dasapta Erwin Irawan (dasaptaerwin@outlook.co.id)
}

Abstract. The following paper describes in brief the data set related to our project "Hydrochemical assessment of Semarang Groundwater Quality". All of 58 samples were taken in 1992, 1993, 2003, 2006, and 2007 using well point data from several reports from Ministry of Energy and Mineral Resources and independent consultants. We provided 20 parameters in each samples (sample id, 5 coord $\mathrm{X}$, coord $\mathrm{Y}$, well depth, water level, water elevation, TDS, $\mathrm{pH}, \mathrm{EC}, \mathrm{K}, \mathrm{Ca}, \mathrm{Na}, \mathrm{Mg}, \mathrm{Cl}, \mathrm{SO}$, $\mathrm{HCO} 3$, year, ion balance, screen location, and chemical facies). The chemical composition were tested in the Water Quality Laboratory, Universitas Diponegoro using mas spectrofotometer method.

The statistical treatment for the dataset (available on Zenodo doi:10.5281/zenodo.57293) were described as follows: (1) data preparation in to csv file format, load it in to R environment; (2) data treatment, including: correlation matrix, cluster analysis using kmeans and hierarchical cluster analysis, and principal component analysis. For analysis and visualizations, We used the following R packages: ggplot2, dplyr, factomineR, factoExtra, cluster, ggcorrplot, and ape.

\section{Introduction}

The following paper describes in brief the data set related to our project "Hydrochemical assessment of Semarang Groundwater Quality". The aim of this project is to understand the water quality classification and distribution in Semarang area and to explain the underlying processes. This analysis is very important with the vast development of infrastructure (Putranto and Rüde (2016)) and urban settlement in coastal area and the rate of salinity encroachment (Rahmawati and Marfai (2013)). The location of the study is Semarang area, Indonesia. 


\section{General description of the dataset}

\subsection{Samples}

All of 58 taken in 1992, 1993, 2003, 2006, and 2007 in 1992, 1993, 2003, 2006, and 2007 using well point data from several reports from Ministry of Energy and Mineral Resources and independent consultant. We provided 20 parameters in each samples: sample id, coord X, coord Y, well depth, water level, water elevation, TDS, pH, EC, K, Ca, Na, Mg, Cl, SO4, HCO3, year, ion balance, screen location, and chemical facies.

The chemical composition were tested in the Water Quality Laboratory, Universitas Diponegoro using mass spectrofotometer method. The laboratory procedures followed the SNI (Indonesia National Standard) for water quality measurement (BSN (2012)), which is comply to the US-EPA standards. The original dataset is available on Zenodo (Irawan and Putranto (2016)).

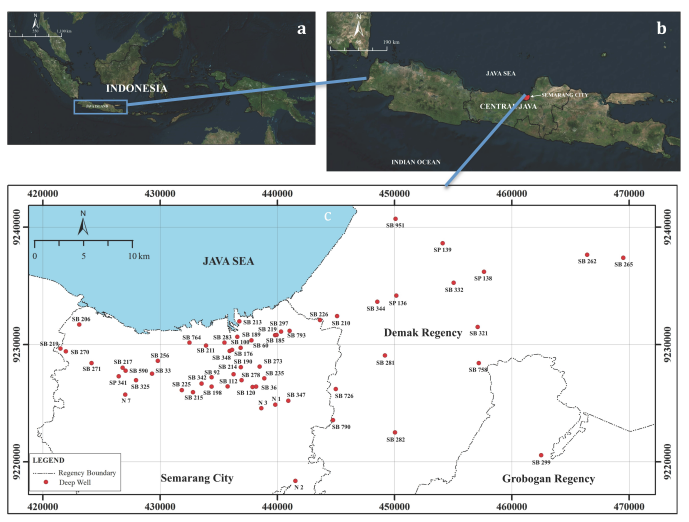

Figure 1. The location of well point and the Stiff diagram

\subsection{The value of dataset}

The following list describes the value of the dataset:

- It provides the current setting of water quality as the baseline of environmental monitoring of the area and serves as a source of groundwater quality indicator for the regional planning of the area,

- It promotes the importance of open government dataset and enriches the library of water quality dataset of the area,

- It sets an example of data re-use and re-analysis in hydrogeological research landscape. 
Earth Syst. Sci. Data Discuss., doi:10.5194/essd-2016-29, 2016

Manuscript under review for journal Earth Syst. Sci. Data

Published: 28 July 2016

(c) Author(s) 2016. CC-BY 3.0 License.

\section{Geographical coverage}

The sampling area is Semarang area, the capital of Mid Java Province, Java, Indonesia. The sampling points were distributed from the southern volcanic highland to the coastal area. The coordinate of the area is $(420000,9240000)$ and $(470000,9220000)$. We plotted the data points using UTM-WGS84$48 \mathrm{~S}$ projection system.

\section{Statistical design}

The hierarchical cluster analysis (HCA) and principal component analysis (PCA) are both widely used in the hydrochemical analysis (Adams et al. (2001); King et al. (2014); Ayenew et al. (2009); Deon et al. (2015); Wilkinson (2014); Maechler et al. (2016)). We have applied the two approaches on groundwater in volcanic area on various locations (Irawan et al. (2009); Herdianita et al. (2010)).

The R implementation was based on Coghlan (2009).

\subsection{Data preparation}

The dataset was formatted in the csv (comma separated value) before parsed in to $\mathrm{R}$ program ( $\mathrm{R}$ Core Team (2016)) for analysis using the following R packages: ggplot2 (Wickham (2009)), dplyr (Wickham and Francois (2016)), factomineR (Lê et al. (2008)), factoExtra (Kassambara and Mundt (2016)), cluster (Maechler et al. (2016)), ggcorrplot (Kassambara (2016)), and ape (Paradis et al. (2004)).

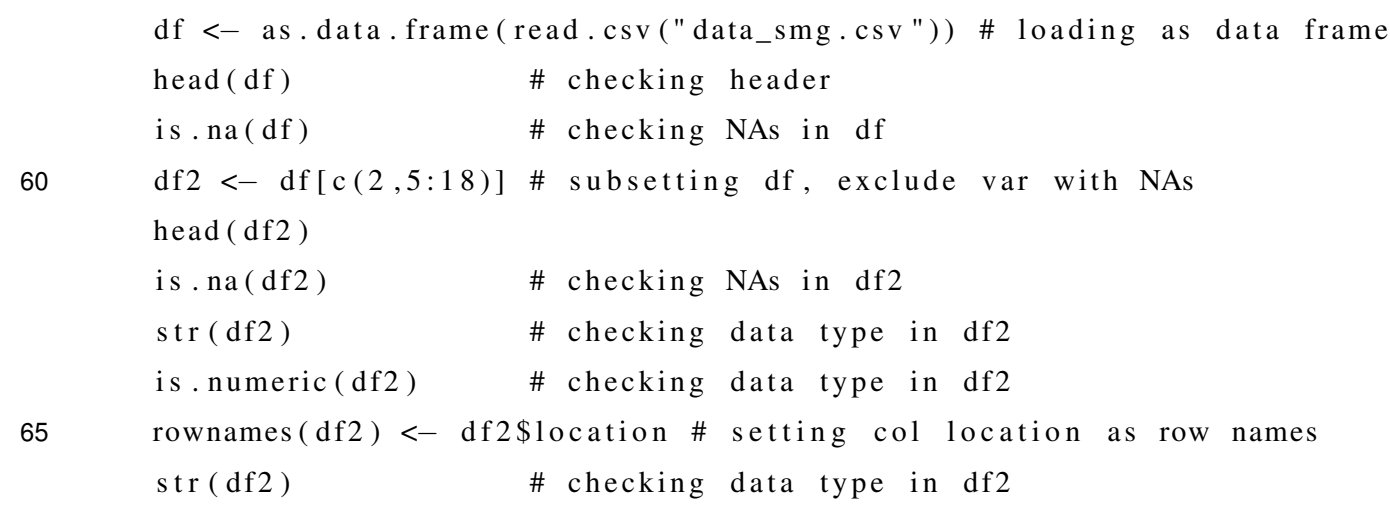

\subsection{Data treatment}

The dataset was treated using the following method: correlation matrix, HCA, and PCA. the steps and $\mathrm{R}$ code can be described below. 
Earth Syst. Sci. Data Discuss., doi:10.5194/essd-2016-29, 2016

Manuscript under review for journal Earth Syst. Sci. Data

Published: 28 July 2016

(c) Author(s) 2016. CC-BY 3.0 License.

(c) (i)

\subsubsection{Correlation matrix}

Here we used PerformanceAnalytics and ggcorrplot packages to build a correlation matrix. The following is the code.

\#\# using PerformanceAnalytics

install packages ("PerformanceAnalytics ")

75

library (PerformanceAnalytics)

chart. Correlation (df2, histogram=TRUE, pch=19) \# visual PA

\#\# using ggcorrplot

install packages ("ggcorrplot")

80

library (ggcorrplot)

correl <- round $(\operatorname{cor}(\mathrm{df} 2), 1) \quad \#$ rounding correl matrix

head ( correl [, 1:14])

\# view headers

p. mat $<-$ cor_pmat (df2)

\# compute p-values

head (p.mat $[, 1: 14])$

\# view headers

85

ggcorrplot ( correl)

\# making heatmap

\subsubsection{Hierarchical cluster analysis (CA)}

We build the CA using k-means and hierarchical clustering by implementing R base function and factoextra package, based on the following code.

install.packages (" factoextra")

\#install_github ("kassambara/factoextra")

install. packages (" cluster")

library ( cluster)

library (factoextra)

95

\#\#\# $\mathrm{k}$ means method

km2 <- kmeans (df2, 2, nstart = 25) \# kmeans with 2 centers

km3 <- kmeans (df2, 3, nstart = 25) \# kmeans with 3 centers

$\mathrm{km} 2 \$$ cluster

$\mathrm{km} 2 \$$ centers

\# extracting cluster number

\# extracting cluster means (or centers)

100

plotkm $2<-$ plot $($ df2,

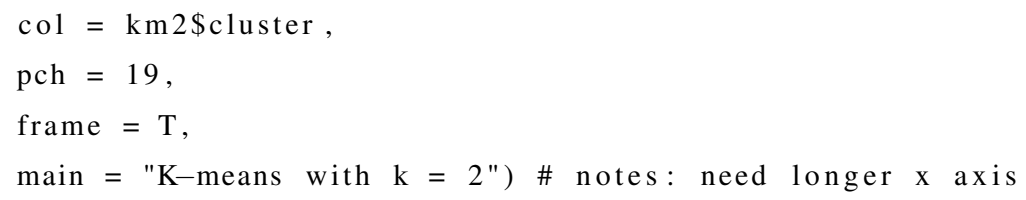


Earth Syst. Sci. Data Discuss., doi:10.5194/essd-2016-29, 2016

Manuscript under review for journal Earth Syst. Sci. Data

Published: 28 July 2016

(c) Author(s) 2016. CC-BY 3.0 License.

110

115

125

130

135

140

120 km 3 \$cluster

$\mathrm{km} 3$ \$centers

\# extracting cluster number

\# extracting cluster means (or centers)

plotkm $3<-$ plot $($ df2,

col $=\mathrm{km} 3 \$$ cluster,

$\mathrm{pch}=19$,

frame $=\mathrm{T}$,

main $=" \mathrm{~K}$-means with $\mathrm{k}=3 "$ )

points ( km3\$centers,

$$
\begin{aligned}
& \operatorname{col}=1: 2, \\
& \text { pch }=8, \\
& \operatorname{cex}=3)
\end{aligned}
$$

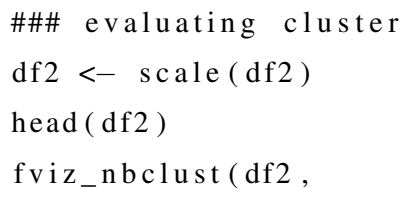


Earth Syst. Sci. Data Discuss., doi:10.5194/essd-2016-29, 2016

Manuscript under review for journal Earth Syst. Sci. Data

Published: 28 July 2016

(c) Author(s) 2016. CC-BY 3.0 License.

(c) (i)

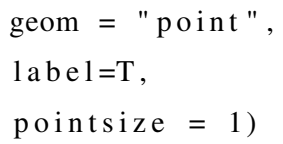

145

\#\#\# Creating dendogram

distdf 2 . res $<-$ dist $($ df 2 , method = "euclidean ")

hcadf $2<-$ hclust (distdf 2 .res,

150 method $=$ "complete")

plot (hcadf2,

$$
\text { hang }=-1) \quad \# \text { dendogram vis }
$$

rect. hclust ( hcadf 2 ,

155

$$
\mathrm{k}=3 \text {, }
$$

$$
\text { border }=2: 4) \# \text { dendogram vis with grouping }
$$

160

\#\#\# using nbclust pack to evaluate no of cluster

install.packages("NbClust") \# for more precise no of cluster

library ("NbClust")

resdf2.nb $<-$ NbClust (df2,

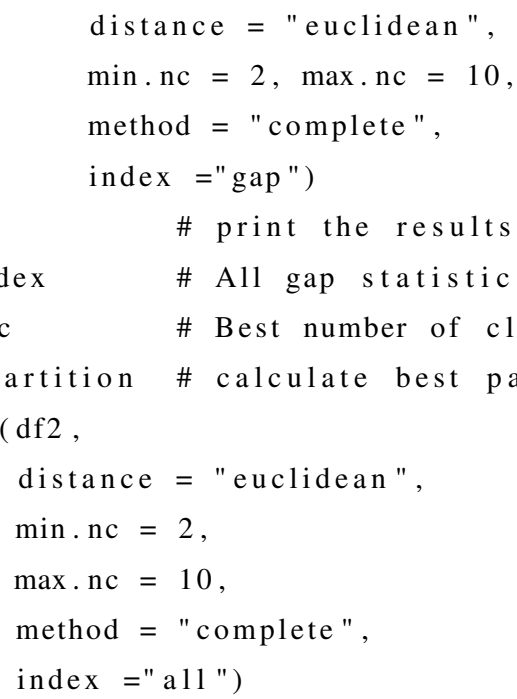

$175 \quad$ nbdf 2

fviz_nbclust (nbdf2) + theme_minimal()

dev. off ()

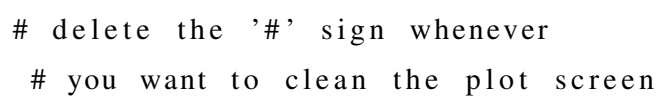


Earth Syst. Sci. Data Discuss., doi:10.5194/essd-2016-29, 2016

Manuscript under review for journal Earth Syst. Sci. Data

Published: 28 July 2016

(c) Author(s) 2016. CC-BY 3.0 License.

(c) (i)

hcadf $2<-$ hclust (distdf 2 .res, method $=$ "complete")

plot (hcadf2,

$$
\text { hang }=-1) \quad \text { \# dendogram vis }
$$

185 rect. hclust ( hcadf2,

$\mathrm{k}=3$,

border $=2: 4)$ \# dendogram vis with grouping

\#\#\#\# rotating the plot

190

\#\#\#\# using ape

\# load package ape; remember to install it: install.packages('ape')

install packages (" ape")

library (ape)

195

plot (as . phylo (hcadf2),

$\operatorname{cex}=0.9$,

label. offset $=1$,

type $=$ "unrooted ")

200

plot (as . phylo (hcadf2),

$\operatorname{cex}=0.9$,

label. offset $=1$ )

\subsubsection{Principal component analysis (PCA)}

The PCA is applied using R base function and visualized using factominer and factoextra

packages. The following is the code.

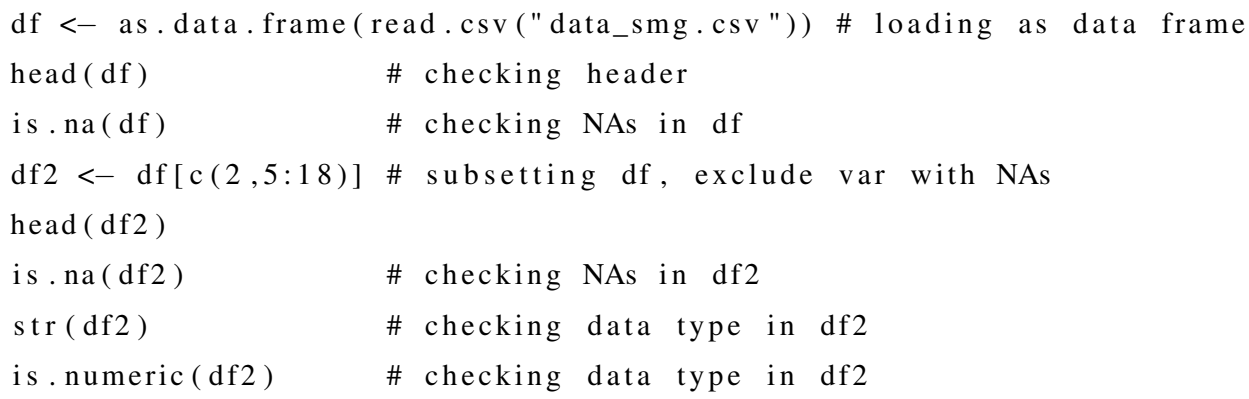


Earth Syst. Sci. Data Discuss., doi:10.5194/essd-2016-29, 2016

Manuscript under review for journal Earth Syst. Sci. Data

Published: 28 July 2016

(c) Author(s) 2016. CC-BY 3.0 License.

(c) (i)

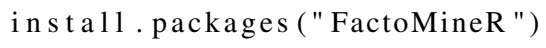

fviz_pca_biplot(res.pca, geom = "text")

\section{Conclusions}

The present study integrates geological, hydrogeological data, and statistical analysis to construct a hydrogeological model of the aquifer system in Semarang. The statistical treatment shows a consistent pattern of anomalous setting at well point 37 (University Sultan Agung 2/Unisula-2). The anomaly needs more in depth analysis to understand the underlying processes in the groundwater flow.

This paper is one of our preliminary example of data paper in Indonesia. Hopefully this can trigger more data papers to endorse open science in our country. 
Earth Syst. Sci. Data Discuss., doi:10.5194/essd-2016-29, 2016

Manuscript under review for journal Earth Syst. Sci. Data

Published: 28 July 2016

(c) Author(s) 2016. CC-BY 3.0 License.

(c) (i)

Acknowledgements. The authors are thankful to the Department of Energy and Resources of Central Java

250 Province and Geological Agency in Bandung for providing hydrogeological data. Hopefully this paper will initiate a mass movement on open government data and data reuse in Indonesia. 
Earth Syst. Sci. Data Discuss., doi:10.5194/essd-2016-29, 2016

Manuscript under review for journal Earth Syst. Sci. Data

Published: 28 July 2016

(c) Author(s) 2016. CC-BY 3.0 License.

(c) (i)

\section{References}

Adams, S., Titus, R., Pietersen, K., Tredoux, G., and Harris, C.: Hydrochemical characteristics of aquifers near Sutherland in the Western Karoo, South Africa, Journal of Hydrology, 241, 91-103, 2001.

Ayenew, T., Fikre, S., Wisotzky, F., Demlie, M., and Wohnlich, S.: Hierarchical cluster analysis of hydrochemical data as a tool for assessing the evolution and dynamics of groundwater across the Ethiopian rift, International journal of physical sciences, 4, 76-90, http://www.academicjournals.org/journal/IJPS/article-abstract/ D64DFAE18634, 2009.

BSN: Standard tests for water sample, Tech. rep., National Board for Standards, http://sisni.bsn.go.id/index. php/sni_main/sni/detail_sni/7689, 2012.

Coghlan, A.: Little Book of R for Multivariate Analysis! — Multivariate Analysis 0.1 documentation, Wellcome Trust Sanger Institute, Cambridge, U.K., https://little-book-of-r-for-multivariate-analysis.readthedocs.io/en/ latest/, affiliation: Wellcome Trust Sanger Institute, Cambridge, U.K., 2009.

Deon, F., Förster, H.-J., Brehme, M., Wiegand, B., Scheytt, T., Moeck, I., Jaya, M., and Putriatni, D.: Geochem$\mathrm{ical} / \mathrm{hydrochemical} \mathrm{evaluation} \mathrm{of} \mathrm{the} \mathrm{geothermal} \mathrm{potential} \mathrm{of} \mathrm{the} \mathrm{Lamongan} \mathrm{volcanic} \mathrm{field} \mathrm{(Eastern} \mathrm{Java,}$ Indonesia), Geothermal Energy, 3, 1-21, doi:10.1186/s40517-015-0040-6, 2015.

Herdianita, N. R., Julinawati, T., and Amorita, I. E.: Hydrogeochemistry of Thermal Water from Surface Manifestation at Gunung Ciremai and Its Surrounding, Cirebon, West Java-Indonesia, in: Proceedings World Geothermal Congress 2010, http://www.geothermal-energy.org/pdf/IGAstandard/WGC/2010/1476. pdf, 2010

Irawan, D. E. and Putranto, T. A.: Dataset: hydrochemical assessment of Semarang area, Indonesia, doi:10.5281/zenodo.57293, http://dx.doi.org/10.5281/zenodo.57293, 2016.

Irawan, D. E., Puradimaja, D. J., Notosiswoyo, S., and Soemintadiredja, P.: Hydrogeochemistry of volcanic hydrogeology based on cluster analysis of Mount Ciremai, West Java, Indonesia, Journal of hydrology, 376, 221-234, http://www.sciencedirect.com/science/article/pii/S002216940900434X, 2009.

Kassambara, A.: ggcorrplot: Visualization of a Correlation Matrix using 'ggplot2', https://CRAN.R-project. org/package=ggcorrplot, $\mathrm{r}$ package version $0.1 .1,2016$.

Kassambara, A. and Mundt, F.: factoextra: Extract and Visualize the Results of Multivariate Data Analyses, https://CRAN.R-project.org/package=factoextra, $\mathrm{r}$ package version 1.0.3, 2016.

King, A. C., Raiber, M., and Cox, M. E.: Multivariate statistical analysis of hydrochemical data to assess alluvial aquifer-stream connectivity during drought and flood: Cressbrook Creek, southeast Queensland, Australia, Hydrogeology Journal, 22, 481-500, doi:10.1007/s10040-013-1057-1, http://link.springer.com/ 10.1007/s10040-013-1057-1, 2014.

Lê, S., Josse, J., and Husson, F.: FactoMineR: A Package for Multivariate Analysis, Journal of Statistical Software, 25, 1-18, doi:10.18637/jss.v025.i01, 2008.

Maechler, M., Rousseeuw, P., Struyf, A., Hubert, M., and Hornik, K.: cluster: Cluster Analysis Basics and Extensions, r package version 2.0.4 - For new features, see the 'Changelog' file (in the package source), 2016.

Paradis, E., Claude, J., and Strimmer, K.: APE: analyses of phylogenetics and evolution in R language, Bioinformatics, 20, 289-290, 2004. 
Earth Syst. Sci. Data Discuss., doi:10.5194/essd-2016-29, 2016

Manuscript under review for journal Earth Syst. Sci. Data

Published: 28 July 2016

(c) Author(s) 2016. CC-BY 3.0 License.

(c) (i)

Putranto, T. and Rüde, T.: Hydrogeological Model of an Urban City in a Coastal Area, Case study: Semarang, Indonesia, Indonesian Journal on Geoscience, 3, 17-27, https://ijog.geologi.esdm.go.id/index.php/ IJOG/article/view/227, 2016.

R Core Team: R: A Language and Environment for Statistical Computing, R Foundation for Statistical Computing, Vienna, Austria, https://www.R-project.org/, 2016.

Rahmawati, N. and Marfai, M.: Salinity Pattern in Semarang Coastal City: An Overview, Indonesian Journal of Geosciences, 8, doi:10.17014/ijog.3.1.17-27, https://ijog.geologi.esdm.go.id/index.php/IJOG/article/ view/160, 2013.

Wickham, H.: ggplot2: Elegant Graphics for Data Analysis, Springer-Verlag New York, http://ggplot2.org, 300 2009.

Wickham, H. and Francois, R.: dplyr: A Grammar of Data Manipulation, https://CRAN.R-project.org/package= dplyr, r package version 0.5.0, 2016.

Wilkinson, D. J.: Multivariate Data Analysis using R: a course notes, Tech. rep., https://www.staff.ncl.ac.uk/d. j.wilkinson/teaching/mas8381/notes14.pdf, 2014. 